\title{
A Gamification Model to Encourage Positive Healthcare Behaviours in Young People with Long Term Conditions
}

\author{
Andrew S. Wilson ${ }^{1, *}$ and Janet E. McDonagh ${ }^{2}$ \\ ${ }^{1}$ School of Computing, Telecommunications and Networks. Faculty of Technology, Engineering and the Environment. \\ Birmingham City University, Millennium Point, Curzon Street, Birmingham. B4 7XG. UK \\ ${ }^{2}$ University of Birmingham \& Birmingham Children's Hospital NHS Foundation Trust. Steelhouse Lane, Birmingham B4 \\ $6 \mathrm{NH}$ UK.
}

\section{Abstract}

Young people living with long term conditions will eventually have to transfer their care to the adult setting. Failure to plan and coordinate this has been associated with poorer health outcomes and disruption to their care. Transition planning encourages both health literacy and health promoting behaviours in an age and developmentally appropriate way. In order to gauge the attainment of these skills the Birmingham Children's Hospital Adolescent Rheumatology Team (UK) have developed a series of transitional care checklists. This paper focuses on discussing how the application of gamification (using game mechanics in non-game contexts) to these checklists could improve the engagement of young people in managing their self-care and provide a mechanism for doctors to quantifying the acquisition of these skills.

Keywords: Gamification, adolescent, chronic conditions, transitional care, self-care

Received on 11 December 2013, accepted on 05 March 2014, published on 22 May 2014

Copyright (c) 2014 Wilson and McDonagh, licensed to ICST. This is an open access article distributed under the terms of the Creative Commons Attribution licence (http://creativecommons.org/licenses/by/3.0/), which permits unlimited use, distribution and reproduction in any medium so long as the original work is properly cited.

doi: 10.4108/sg.1.2.e3

\section{Introduction}

With advances in healthcare people living with medical conditions such as asthma, diabetes, arthritis, cancer, cystic fibrosis, inflammatory bowel disease, congenital heart disease and after organ transplantation can expect to live longer and have healthier lives. The absence of a cure for these long term conditions means that in order to maintain positive health outcomes changes in behaviour for example adopting a healthier lifestyle (improving diet and taking exercise) as well as learning appropriate self-care skills are extremely important. This can be challenging for many people and potentially more so when the person diagnosed is relatively young. It is estimated that 1 in $711-15$ year olds in England live with a long term medical condition [1] which may persist with them into their adult years.

Clinical care for young people who are diagnosed with a medical condition at an early age starts in an environment

"Corresponding author. Email: andrew.wilson@bcu.ac.uk that is family centred. As the young person grows older they will eventually have to transfer to the adult healthcare setting. There is no set age for this in the UK but it normally occurs between 16 and 18 years of age. However it is more dependent upon local hospital policy rather than the young person's confidence in being able to cope in the adult healthcare setting.

Transfer of care can be a cause of anxiety to both the young person and their family. This may be due to the change to a new physical location; they have to become familiar with a different style of healthcare environment and have to work with an unfamiliar clinical team. Studies investigating the pre-transfer period identified an increased risk for negative health outcomes if the transfer process was not appropriately managed. This included both increased incidence of graft loss in organ transplant patients [2] and an increased chance of mortality in them [3], worsening disease activity in young people with long term rheumatic conditions [4], or they are just lost in the healthcare system and consequently fail to attend clinics [5][6]. Those that 
experience such lapses in healthcare have also been reported to have an increased risk of subsequent readmission to hospital [6][7]. Even in those with stable disease, poorer vocational outcomes have been reported post transfer [8].

In order to improve the chances for successful transfer it is accepted that the process should not be abrupt but purposely planned, taking into account the developmental status and readiness of the young person to negotiate the adult healthcare system [9]. This is known as transitional care and addresses the medical, psychosocial as well as educational and vocational needs of the young person. The Birmingham Children's Hospital (BCH) Adolescent Rheumatology Team (UK) have produced a series of readiness checklists for early, mid and late adolescence which are used to help gauge how well the young person is progressing towards understanding their condition, its treatment and how to look after themselves. Education forms an important part of this but many young people and their families find it difficult to get the information they need and it is not always in appropriate style for them [10]. Therefore there is interest in how information can be presented in a youth friendly way and how technology can be used to support this [11].

The internet has become an important source of health related information for young people and one in which they can actively participate for example by influencing the development of youth-centred online healthcare programmes [12][13]. It has also been recognised that with the growth of new forms of communication for example social marketing, creative design and information technology can be used as a way of communicating information and supporting young people's developmental and healthcare needs [14][15].

One medium that has become a big part of many young people's lives is video games. This has seen the emergence of computer games which have combined both the entertainment and education aspects with a view to engaging people in subjects which might normally be difficult to communicate by other means. Computer games have been successfully developed to help young people, who are living with long term conditions, understand their condition, how it is treated and to support them in learning important self-care skills. Examples include Packy \& Marlon and Captain Novolin which were developed in the mid 1990s for the Nintendo Entertainment System and were aimed at teaching young people how to manage their diabetes [16]. Creep Frontier combines physical interaction with the game through a spirometer so that young people with cystic fibrosis can learn to control their breathing [17]. Re-Mission and Re-Mission2 are a series of games that have been designed to teach young people about their cancers, their treatment and how to effectively care for themselves [18]. The authors have previously reviewed a range of healthcare games for young people [19]. From the literature we identified that many games had been created, not all had been formal evaluated but those that had, had resulted in positive benefits to the young people. However we also identified that many of the games focussed on specific medical conditions and issues relating these. Therefore they would not necessarily provide all the information needed that is associated with the complex issues of transitional care.

Another factor in the development of computer games is the time and cost of their development. An alternative approach that takes advantage of the principles of games (fun) would be applying game mechanics to the process of knowledge and skill acquisition that are involved in transitional care. This principle is known as gamification and uses game techniques in non-game contexts.

In this paper we will review the issues that are associated with transitional care, provide an overview of how transitional readiness is assessed and how gamification could be applied to the BCH Adolescent Rheumatology Team (UK) transition readiness check lists. We will discuss how this would provide an objective framework for the clinical team as well as encapsulating the processes in a more fun way in order to engage young people in understanding their medical conditions and encouraging them to actively participate in learning about and acquiring self-care skills.

\section{Young people and transitional care}

Young people who are diagnosed with a long term condition at an early age may live with it through their adolescent years and into adulthood. As the young person grows older and enters different stages of adolescence the knowledge and skills they need to acquire in order to take care of themselves will evolve. There will also be a shift in the responsibility for care from their parents to themselves.

Adolescence is already a difficult time for many young people as they become increasingly independent and assume adult roles and responsibilities. It is also a time when patterns of health promoting as well as health risk behaviours include eating, physical activity, and sexual activity are established and can be maintained throughout life [14]. Health risk behaviours can be more common in young people with long term conditions [20] and consequently have a greater potential for adverse health outcomes [14].

It has been acknowledged by the healthcare community that young people are a distinct group and should have healthcare focussed towards their specific needs. This includes age and developmentally appropriate preparation for transfer of their healthcare to the adult setting [9]. Panel 1 highlights the range of knowledge and skills that have been identified as being important for young people to be able to successfully function in the adult healthcare system. 
Panel 1. Knowledge and skills to enable young people to function successfully in the adult healthcare system

Disease education: e.g. being able to understanding the symptoms and prognosis of their condition; the rationale for treatments and their potential side-effects; increasing confidence to self-manage including keeping clinical appointments and adhering to treatments.

Psychological health: e.g. being able to manage emotions (including anger), body image issues and feelings of 'difference'.

General health: e.g. Engaging in physical activity and healthy eating. Understand issues of substance use; and issues relating to sexual and reproductive health including implications with long term conditions.

Healthcare services: e.g. Maximising use of clinic appointments; understanding their rights to privacy and confidentiality; seeing professionals independently of parents; communicating, listening and challenging healthcare providers; accessing health services for advice; understanding differences between child and adult centred services; understanding of the transition process.

Social issues: e.g. Minimising the impact on their family and friends as well as reducing impact on the things they enjoy doing. Dealing with disclosure, social isolation, bullying, social stigma and access issues.

Education: e.g. Maximising attendance, academic performance and peer involvement. Gaining access to educational support including their statutory entitlements. Managing within the built environment and optimising educational options (including higher and further education).

Vocation: e.g. Making appropriate career choices; work experience, knowledge of rights and resources.

Independent living: Development of skills for independence including mobility, driving and independent travel.

The optimal timeframe when these skills should be acquired by the young person is not set rather it is dependent both upon their confidence in the skills as well as their cognitive ability. La Rosa and colleagues [21] have outlined types of knowledge and skill acquisition which they believe are important for young people with organ transplants to have during different age and developmental stages. They suggest that during childhood they should be able to understand their condition and need for treatment, during early adolescence they should understand side effects associated with their treatment and the need for urgent care, whereas young adults should be able to schedule their own appointments, communicate with their care team and understand the need to move their care to adult centres (Figure 1).

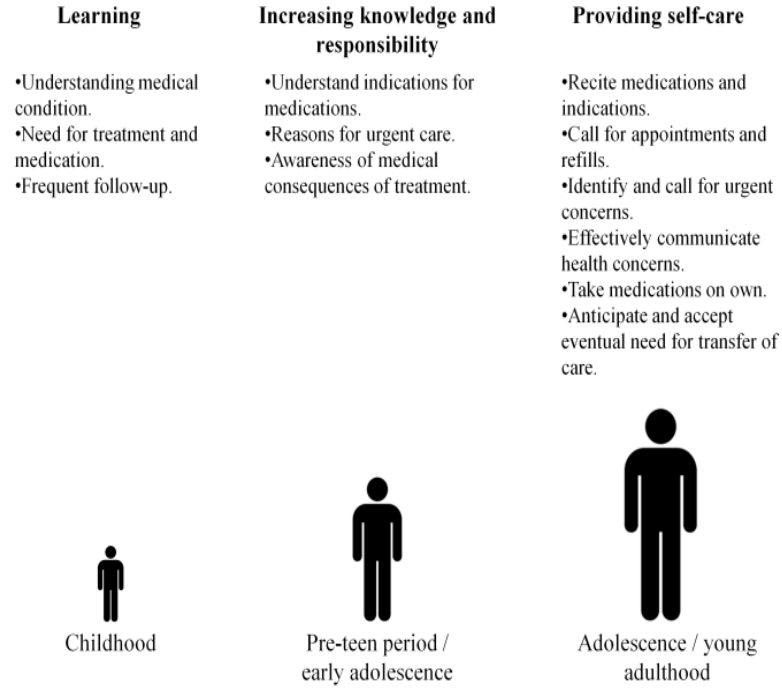

Figure 1. A time line of knowledge and skill acquisition for young people with solid-organ transplants. Adapted from La Rosa and colleagues (2011).

Gauging a young person's readiness to transfer their healthcare depends upon their self-belief as well as the involvement of the parents and the healthcare team. Monitoring and assessing competency in self-care and selfmanagement skills has seen the development of transitional readiness assessment tools which have been designed to help evaluate a young person's progress towards acquiring these self-care and self-management skills.

\section{Measurements of readiness to transition}

Several transitional readiness assessment tools including the Paediatric Transition Readiness Score (PTRS) and Pediatric Acceptance Readiness Score (PARS) [21], Transition Readiness Assessment Questionnaire (TRAQ) [22] and The University of North Carolina (UNC) $\operatorname{Tr}_{\mathrm{x}}$ ansition Scale [23] have been developed to assist in ascertaining transitional readiness. Many of the items in these tools are common to one another for example understanding the medical condition and its treatment, self-care and self-management, communicating with the healthcare team and understanding how to use support services. However these assessments can be disease specific and have aspects that are more relevant to their country of origin for example managing the medical insurance and financial aspects of healthcare.

In order to focus on issues relating to healthcare in the UK the BCH Adolescent Rheumatology Team have produced and evaluated series of transitional readiness checklist for young people with rheumatic disease. "Getting ready!”, "Moving along!” and "Moving up!” [24]. These reflect a series of self-care skills associated with early, mid and late adolescence. The knowledge and skills they assess are in eight domains which include knowledge, selfadvocacy, transferring to adult healthcare as well as 
understanding how to manage their health and lifestyle. They also include activities relating to daily living, school and vocation, and leisure as well as being able to manage emotions. These eight domains assess 24, 32 and 35 different knowledge and self-management skills in early, mid and late adolescence respectively. Although not formally validated they continue to be used with all young people attending the adolescent rheumatology service from age 11 years irrespective of condition.

Table 1 are examples of the types of task that are assessed in the knowledge, self-advocacy and health and lifestyle domains.

Table 1. Example tasks in the $\mathrm{BCH}$ Adolescent Rheumatology Team's (UK) early, mid and late adolescent readiness checklists for transitional care.

\begin{tabular}{|c|c|c|c|}
\hline & $\begin{array}{l}\text { Early } \\
\text { Adolescent Plan }\end{array}$ & $\begin{array}{l}\text { Mid Adolescent } \\
\text { Plan }\end{array}$ & $\begin{array}{l}\text { Late Adolescent } \\
\text { Plan }\end{array}$ \\
\hline \multirow[t]{3}{*}{ Knowledge } & $\begin{array}{l}\text { I can describe } \\
\text { my condition }\end{array}$ & $\begin{array}{l}\text { I understand the } \\
\text { medical } \\
\text { terms/words and } \\
\text { procedures } \\
\text { relevant to my } \\
\text { condition }\end{array}$ & $\begin{array}{l}\text { I am confident in } \\
\text { my knowledge } \\
\text { about my } \\
\text { condition and its } \\
\text { therapy }\end{array}$ \\
\hline & $\begin{array}{l}\text { I know my } \\
\text { medication } \\
\text { regime - names, } \\
\text { doses, how often } \\
\text { etc }\end{array}$ & $\begin{array}{l}\text { I understand } \\
\text { what each of my } \\
\text { medications are } \\
\text { for and their side } \\
\text { effects }\end{array}$ & $\begin{array}{l}\text { I look after my } \\
\text { own medication }\end{array}$ \\
\hline & & $\begin{array}{l}\text { I know about } \\
\text { resources that } \\
\text { offer support for } \\
\text { young people } \\
\text { with my } \\
\text { condition }\end{array}$ & $\begin{array}{l}\text { I call the hospital } \\
\text { myself if there is } \\
\text { a query about } \\
\text { my condition } \\
\text { and/or therapy }\end{array}$ \\
\hline \multirow[t]{2}{*}{$\begin{array}{l}\text { Self- } \\
\text { Advocacy }\end{array}$} & $\begin{array}{l}\text { I feel ready to } \\
\text { start preparing to } \\
\text { be seen alone for } \\
\text { part of the clinic } \\
\text { visit in the future }\end{array}$ & $\begin{array}{l}\text { I feel confident } \\
\text { to be seen on my } \\
\text { own for some/all } \\
\text { of each clinic } \\
\text { visit }\end{array}$ & $\begin{array}{l}\text { I feel confident } \\
\text { to be seen on my } \\
\text { own in clinic }\end{array}$ \\
\hline & $\begin{array}{l}\text { I ask my own } \\
\text { questions in } \\
\text { clinic }\end{array}$ & $\begin{array}{l}\text { I understand my } \\
\text { rights and } \\
\text { responsibility } \\
\text { to privacy, } \\
\text { decision-making, } \\
\text { consent and } \\
\text { confidentiality }\end{array}$ & $\begin{array}{l}\text { I understand my } \\
\text { rights and } \\
\text { responsibility to } \\
\text { privacy, } \\
\text { decision-making, } \\
\text { consent and } \\
\text { confidentiality }\end{array}$ \\
\hline $\begin{array}{l}\text { Health \& } \\
\text { Lifestyle }\end{array}$ & $\begin{array}{l}\text { I understand the } \\
\text { importance of } \\
\text { exercise/ } \\
\text { activity for both } \\
\text { my general } \\
\text { health and my } \\
\text { condition }\end{array}$ & $\begin{array}{l}\text { I exercise } \\
\text { regularly/ } \\
\text { have an active } \\
\text { lifestyle }\end{array}$ & $\begin{array}{l}\text { I exercise } \\
\text { regularly/have } \\
\text { an active } \\
\text { lifestyle }\end{array}$ \\
\hline
\end{tabular}
stage of adolescence and is reflected in the style of the question. The young person will respond as to whether they can do the task on their own or that they would like some extra help with this the particular item.

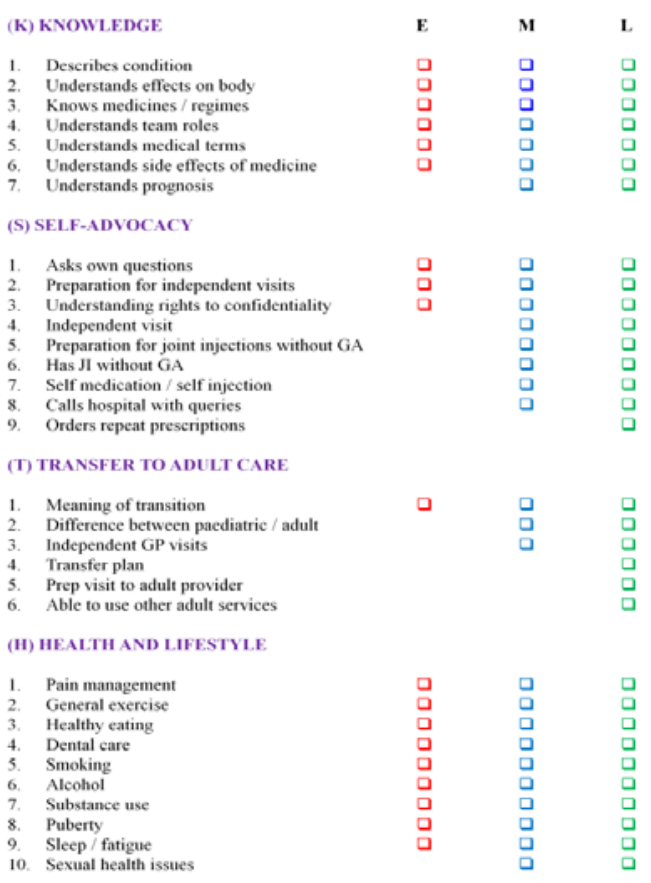

Figure 2. A subset of four domains and individual items assessed in the health professional checklist for gauging young person's transitional readiness. E, M and $L$ denote early, mid and late adolescent development.

The rheumatology professional will record the responses on their own checklist as a means of monitoring overall progress of the young person (Figure 2).

The adolescent checklists are based on self-reporting with the views of the young person taking precedence over those 
of the clinician. While transitional care monitors the young person's progress toward acquiring knowledge and self-care skills it relies on the young person motivating themselves to maintain their own positive health behaviours. By using gamification the process could be made more fun for the young person and quantitative for the clinician.

\section{Application of gamification to the Birmingham Children's Hospital transitional readiness checklist}

Using the principles found in games in non-game contexts has been termed gamification and is being used in a range of settings including training, education, project management, social networks and in the commercial sector. It has also become of increasing interest in health and wellness as a way of encouraging people to adopt healthier lifestyles for example by taking more exercise and having a healthier diet. Nike Training club (http://www.nike.com/us/en_us/c/womens-

training/apps/nike-training-club) is a mobile app which uses gamification to promote physical activity and maintaining a healthy diet. FitBit (http://www.fitbit.com/), JawBone UP (https://jawbone.com/up/international) and Zamzee (https://www.zamzee.com/) use sensor technology to measure activity and sleep patterns which link to online portals where the player can record their dietary intake and monitor their lifestyle over time. Website such as Playnormous (http://www.playnormous.com/) offer young people games, activities and stories to encourage healthy eating habits. King and co-workers [25] suggest that gamification will become more familiar in healthcare as a result of adoption of smart phones which will provide a rich platform for delivering the content to its audience as well as resulting from the game developer's desire to drive innovation as a result of new behavioural insights into electronic interventions. These approaches have already been explored as a way of engaging young people in learning about sexual transmitted diseases and safe sex practises [26] and have been shown to be successful in improvement in the daily average frequency of blood glucose measurements by $50 \%$ in young people living with Type 1 Diabetes [27].

Gamification is aimed at making routine activities more fun and uses both game dynamics and mechanics, which define the rules of how a game is played, in order to achieve this. Three of the game dynamics progression, feedback and behaviour represent processes that can be used to promote the knowledge, learning and behaviours that are important in acquiring self-management skills. Table 2 illustrate the different types of game dynamic, provides a definition of the game mechanics associated with each of the dynamics and suggestions by the authors of how these could be applied to promote positive self-care and self-management behaviours in young people participating in transitional care.
Table 2. Mapping of gamification mechanics to selfcare behaviours

\begin{tabular}{|c|c|c|c|}
\hline $\begin{array}{l}\text { Game } \\
\text { Dynamic }\end{array}$ & $\begin{array}{l}\text { Game } \\
\text { Mechanic }\end{array}$ & $\begin{array}{l}\text { Mechanic } \\
\text { definition }\end{array}$ & $\begin{array}{l}\text { Examples } \\
\text { relating to self- } \\
\text { care / } \\
\text { management } \\
\text { behaviours }\end{array}$ \\
\hline \multirow[t]{4}{*}{ Progression } & Achievements & $\begin{array}{l}\text { Accomplishments } \\
\text { which are } \\
\text { unlocked after } \\
\text { succeeding in a } \\
\text { given task }\end{array}$ & $\begin{array}{l}\text { Successfully } \\
\text { attaining self- } \\
\text { care and self- } \\
\text { management } \\
\text { skills }\end{array}$ \\
\hline & Levels & $\begin{array}{l}\text { A reward for } \\
\text { amassing points }\end{array}$ & $\begin{array}{l}\text { Attaining more } \\
\text { advanced } \\
\text { knowledge and } \\
\text { skills as the } \\
\text { young person } \\
\text { matures }\end{array}$ \\
\hline & Points & $\begin{array}{l}\text { Numerical values } \\
\text { given to actions }\end{array}$ & $\begin{array}{l}\text { Incentives to } \\
\text { achieve skills } \\
\text { and a measure } \\
\text { of success }\end{array}$ \\
\hline & Progression & $\begin{array}{l}\text { Success as } \\
\text { measured through } \\
\text { the completion of } \\
\text { tasks }\end{array}$ & $\begin{array}{l}\text { Demonstration } \\
\text { that the skills } \\
\text { are being } \\
\text { attained and that } \\
\text { satisfactory } \\
\text { progress is } \\
\text { being made } \\
\text { toward transfer } \\
\text { of care to the } \\
\text { adult system }\end{array}$ \\
\hline \multirow[t]{3}{*}{ Feedback } & Appointments & $\begin{array}{l}\text { A predetermined } \\
\text { time and place to } \\
\text { participate in a } \\
\text { game }\end{array}$ & $\begin{array}{l}\text { Encouraging } \\
\text { regular contact } \\
\text { with the clinical } \\
\text { care team }\end{array}$ \\
\hline & Bonuses & $\begin{array}{l}\text { Rewards for } \\
\text { completing a } \\
\text { series of } \\
\text { challenges }\end{array}$ & $\begin{array}{l}\text { Encouraging } \\
\text { positive } \\
\text { behaviour for } \\
\text { example } \\
\text { adherence to } \\
\text { treatment, } \\
\text { appointments or } \\
\text { demonstrating } \\
\text { acquisition of } \\
\text { skills in a timely } \\
\text { manner }\end{array}$ \\
\hline & $\begin{array}{l}\text { Cascading } \\
\text { Information } \\
\text { Theory }\end{array}$ & $\begin{array}{l}\text { Release of } \\
\text { information in } \\
\text { small parts to } \\
\text { ensure appropriate } \\
\text { levels of } \\
\text { understanding }\end{array}$ & $\begin{array}{l}\text { Providing } \\
\text { information in } \\
\text { an age and } \\
\text { developmentally } \\
\text { appropriate } \\
\text { manner }\end{array}$ \\
\hline
\end{tabular}




\begin{tabular}{|c|c|c|}
\hline Combos & $\begin{array}{l}\text { Undertaking } \\
\text { another action } \\
\text { after successfully } \\
\text { completing a } \\
\text { previous one }\end{array}$ & $\begin{array}{l}\text { Demonstrating } \\
\text { understanding of } \\
\text { a series of skills } \\
\text { or skills that are } \\
\text { associated with } \\
\text { one another for } \\
\text { example } \\
\text { knowing the } \\
\text { types of } \\
\text { medicine they } \\
\text { need to take as } \\
\text { well as their side } \\
\text { effects }\end{array}$ \\
\hline Countdown & $\begin{array}{l}\text { A time limit to } \\
\text { accomplish a task }\end{array}$ & $\begin{array}{l}\text { A way of } \\
\text { encouraging } \\
\text { behaviours } \\
\text { which are } \\
\text { potentially } \\
\text { lagging behind } \\
\text { what would be } \\
\text { expected / } \\
\text { anticipated for } \\
\text { that young } \\
\text { person }\end{array}$ \\
\hline $\begin{array}{l}\text { Reward } \\
\text { schedules }\end{array}$ & $\begin{array}{l}\text { The timeframe } \\
\text { and mechanisms } \\
\text { through which } \\
\text { rewards (points, } \\
\text { prizes, level ups) } \\
\text { are given }\end{array}$ & $\begin{array}{l}\text { Motivation, } \\
\text { incentives and } \\
\text { recognition of } \\
\text { accomplished } \\
\text { tasks and } \\
\text { acquired skills }\end{array}$ \\
\hline $\begin{array}{l}\text { Community } \\
\text { collaboration }\end{array}$ & $\begin{array}{l}\text { The game } \\
\text { community works } \\
\text { together to solve a } \\
\text { riddle, a problem } \\
\text { or a challenge }\end{array}$ & $\begin{array}{l}\text { Providing peer } \\
\text { support, sharing } \\
\text { information and } \\
\text { experiences to } \\
\text { reduce the } \\
\text { feeling of } \\
\text { isolation and } \\
\text { being alone }\end{array}$ \\
\hline Discovery & $\begin{array}{l}\text { The love of } \\
\text { exploring and } \\
\text { discovering } \\
\text { something new } \\
\text { and being } \\
\text { surprised by it }\end{array}$ & $\begin{array}{l}\text { Learning about } \\
\text { their condition, } \\
\text { treatment and } \\
\text { how to manage } \\
\text { their care } \\
\text { independently }\end{array}$ \\
\hline Ownership & $\begin{array}{l}\text { Used to create } \\
\text { loyalty }\end{array}$ & $\begin{array}{l}\text { Taking } \\
\text { responsibility } \\
\text { for self-care as } \\
\text { the emphasis } \\
\text { shifts to the } \\
\text { young person } \\
\text { away from the } \\
\text { parents }\end{array}$ \\
\hline Status & $\begin{array}{l}\text { The rank or level } \\
\text { of a player }\end{array}$ & $\begin{array}{l}\text { Demonstrating } \\
\text { that the person } \\
\text { has achieved the } \\
\text { required skills } \\
\text { and knowledge } \\
\text { in relation to } \\
\text { their peers and } \\
\text { that it is } \\
\text { achievable }\end{array}$ \\
\hline
\end{tabular}

Adapted from Gamification Wiki (source:
http://gamification.org/wiki/Game_Mechanics)

Acknowledging that a patient is an individual and personalizing their healthcare is very important. Therefore the basis of transitional care is a partnership between the young person, their family and the clinical team. This is reflected in the BCH's Adolescent Rheumatology Team checklists which monitor progress and achievements from both the young person's and clinical team's perspectives. Education and feedback are also an integral part of healthcare and forms the basis for positive health behaviours.

The rise in the use of the internet and social media by young people illustrates their importance to them. These media provide a mechanism for delivering healthcare information and monitoring progress which has seen the emergence of online youth-centred health-care programmes which have been created with the input of young people. These websites include interactive activities, self-monitoring and reflection, youth-to-youth information sharing and social support, and accurate, accessible and developmentally targeted health specific information [13]. Features such as discussion boards, stories of hope, and video clips help to provide support and reduce the feelings of isolation in their illness [28]. User generated content forms an important part of personalisation online. By encouraging young people to record their activities by keeping blogs, on line diaries, uploading videos as well as participating in answering questions in online forums gives the young person a way of evidencing how they have been working towards acquiring self-care and self-management skills. This evidence can be mapped to the knowledge and self-management skills associated with the transitional care checklists. Each of the eight domains in the doctor's checklist (Figure 2) has a series of tasks associated with it that are important for the young person to acquire. These self-management skills at each stage of adolescence evolve (Table 1) reflecting the skills which have been identified as being important for successful transfer to adult healthcare settings.
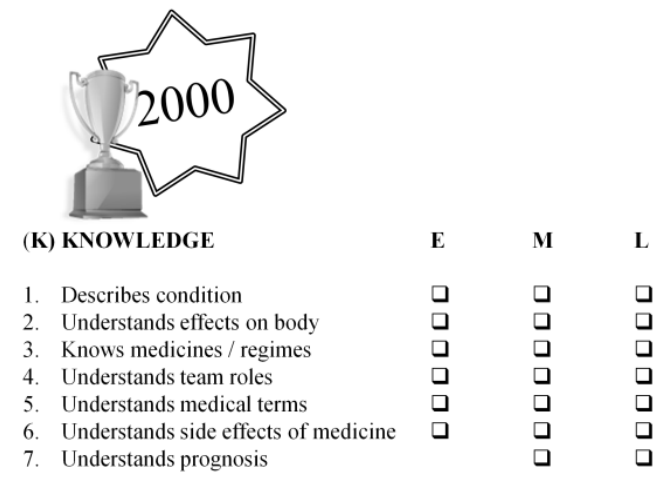

Points
Badges
Level

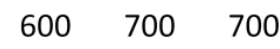

Figure 3. Application of rewards and scoring system to quantify progress toward knowledge and skills acquisition. 
By using the principles of gamification the young person's progress towards acquiring these skills could be quantified and provide a way of monitor their achievements. In the simplest form each of the response at each stage of adolescence would have a value associated with it. Figure 3 illustrates how this may be achieved for the knowledge domain.

There are seven tasks based upon knowledge and up to three different levels of response based upon the stage of adolescence (early, mid or late). An example of how gamification may be applied is that each of the tasks may have 100 points for demonstrating its achievement (a total of 2000 points for the knowledge domain). If the player demonstrates achievement of all tasks associate with early adolescence they would receive 600 points and they would gain a level. More points and higher levels would be achieved as more knowledge is accumulated as the young person matures through the stages of adolescence. When all items within a domain are completed (2000 points and achieving level 3) a further reward, for example a trophy, can be earned signifying mastery of that domain.

Some of the items in the transitional readiness checklists (Figure 2) lend themselves to aggregation for example

- Being able to describe both the condition and effects on the body.

- Knows medicines / regimes and side effects of medicine.

- Preparation for joint injections without general anaesthetic and has joint injections without general anaesthetic.

Acquiring these skills in combination lend themselves to the assignment of bonuses points for successfully achieving all of them together. If these combinations have been completed or completed in a shorter than expected time bonuses would also be rewarded. Where there is a delay in the time that certain skills would be expected to be acquired the countdown mechanic could be used to add an incentive for the young person to engage and acquire those skills.

Many systems that use gamification use rewards as a way of recognising achievements. There is a danger that rewards can be over used devaluing the achievements but if insufficient are used the incentive to engage with the process is lost. Reward schedules and ratios are used to manage this with randomness and surprises being some of the most effective strategies. Badges and trophies are the most common examples of reward however digital prizes, virtual goods and objects found or taken within the course of a game have been used and can be traded or given away giving the game an extra dimension.

Leader boards are a tool used to give a comparison of progress and feedback in relation to others. This can have a positive effect by motivating people to improve their performance. However it can also have negative effects where it is felt that the targets are unachievable. Marczewski [29] suggests the use of both absolute and relative leader boards where the former would indicate progress against all others where the latter would indicate performance within a domain and / or within a developmental stage (i.e. early, mid or late adolescence).

Complementing rewards as a motivating factor is the need to provide feedback to the young person as a way of guiding their progress towards acquiring appropriate healthcare behaviours. The clinical appointment forms an important point of contact for information exchange between doctor and patient and is used to monitor progress and provide feedback. It is not uncommon for people to miss appointments which results in disruption to their care. In order to reinforce the importance of attending clinical appointments additional points would be awarded.

Even if appointments are maintained the time that young people can spend with their doctor can be limited. Therefore other mechanisms of feedback would be needed. On an individual level the incorporation of knowledge quizzes into online health information resources have been recognised as important ways of supporting consolidation of knowledge about medical conditions in young people [30].

Peer feedback would be another way of helping provide support to the community and is an important component of the social and cooperative nature of online games. It must be taken into consideration that feelings of being different and not "fitting in" can occur in young people with long term medical conditions and this can lead to social isolation and stigma. However there is evidence that people with disabilities inhabit online games and virtual worlds as a way of combating this [31]; anonymity can be preserved by the using avatars which are online characters that reflect the player's persona but hide their true identity. The community proposed would be one comprised of young people with long term conditions and secured in order to restrict access to only those who would need it.

\section{Technology and platforms}

Technology is an important medium for many young people with the internet establishing itself as a recognised source of healthcare information for them. It also provides an important mechanism for distributing content and connecting individuals together in our proposed system. One of the requirements will revolve around the healthcare team being able to gather and collate information in order to review the progress and skill acquisition of the young people with respect to their healthcare checklists. Therefore a database would be an appropriate mechanism for storing that information. Linking it to a digital dashboard would provide the clinician with reports on that information. Having a central repository of data means that information can be collected from many patients over time. This will give the healthcare team access to important information that can be used to answer research questions relating to monitoring and improving clinical practice.

The young people also need to be able to participate in the proposed gamified system. It should be available to them in forms that are acceptable to them, allow them to 
contribute to in times that are convenient to them and which are presented in a discrete way which maintains their privacy. Web based systems allow content to be delivered to a range of devices including personal computers, tablets and mobile phones. With the introduction of the fifth version of HyperText Markup Language (HTML 5) improvements have been made allowing the development of media rich content. HTML 5 is also being promoted as a way to distribute content to multiple platforms.

Smart phones are establishing themselves as an integral part of the way young people communicate and maintain their intricate online social networks. They have also received increasing attention as a way of delivering healthcare information to young people [25] and have been shown to be both acceptable to them and successful in engaging them in their self-care [27].

Implementing e-portfolios would be a way for young people to manage their content, review their progress and receive feedback. Figure 4 illustrates how user generated content could contribute to these online portfolios and how they could be used to help evidence how the young people are acquiring knowledge, self-care and self-management skills. The relative leaderboards gauge an individual's progress in a domain with the main leaderboard showing overall progress in their transitional care and how ready they may be to transfer to the adult healthcare system.

Feedback from the clinical care team, parents and peers helps guide and provides support for the young people. Although our framework provides a quantitative mechanism for gauging achievements and progress of the young person in their transitional care it would not supplant their views or how confident and prepared they feel in order to navigate the adult healthcare system.

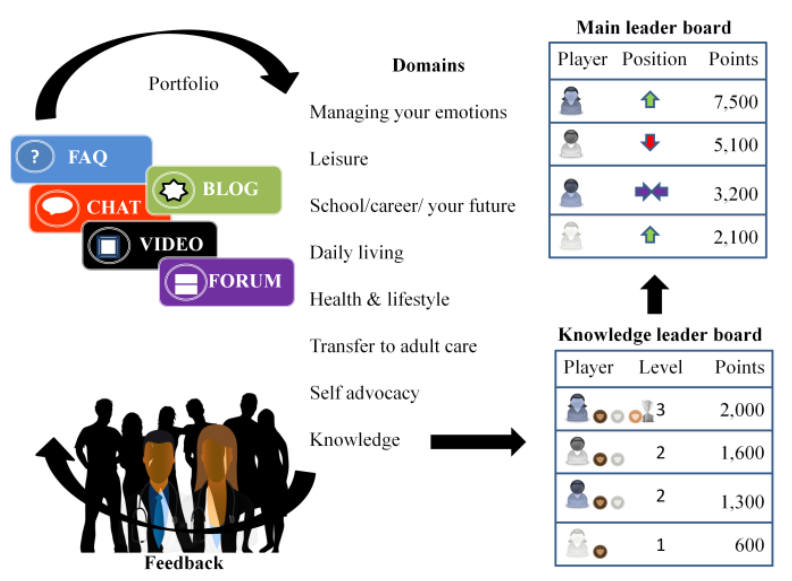

Figure 4. A framework for gamification of transitional care. Individual portfolios are used to evidence skill acquisition, leaderboards inform achievements with feedback helping guide progress towards attainment of knowledge and skills.
One concern that is often raised about technology is it's over use by young people and that it may be detrimental to their health and well-being. There is ongoing debate with evidence arguing for both the positive and negative aspects of exposing young people to prolonged use of technology. A recent survey of over 11,000 young people in the UK did not find that playing computer games increased the risk of behavioural problems in them [32]. A review by Hagell [33] suggests that new technologies should form an important component in health promotion particularly in hard-to-reach groups. Given that technology is embedded in youth culture it may be appropriate to find new and innovative ways of using it as a way of communicating with young people rather than completely avoiding it. However moderation and monitoring young people's interaction with technology is an important consideration.

\section{Evaluation of the gamified system}

In this paper we have proposed a model where gamification could be applied to the $\mathrm{BCH}$ Adolescent Rheumatology Team transitional readiness checklists in order to improve the engagement of young people in their self-care and provide a mechanism for the healthcare team to monitor their progress.

The implementation of the system would initially be dependent upon a qualitative research project exploring the views of young people with long term medical conditions as well as those of the health professionals involved in their care. This would involve exploring the potential of the approach in the context of established transitional care programmes. It would include discussion around the practical implementation in the healthcare setting for example availability in waiting rooms, hospital internet site and how it could be used within a peer support activity setting. Involving the young people in the design at an early stage will be very important to ensure success. Evaluation of the proposed gamified approach would revolve around comparing it against no access in a randomised controlled trail assessing whether there were improvements in the young people's knowledge and self-management skills as a result of gamification. These are future areas of work as they represent significant investigations which would require funding both for the qualitative aspects, the game's development and subsequent evaluation of its implementation. Consideration will also have to be given to ethical approval of such studies owing to the work involving young and potentially vulnerable groups of individuals.

\section{Discussion and conclusion}

Maintaining the engagement of young people in self-care as they grow older is challenging as other factors increasingly become prominent in their lives particularly during adolescence. However the implications of not taking care of themselves are a poorer quality of life and delaying the inevitable transfer of care to the adult system. From the 
clinical teams perspective being able to monitor and assess a young person's competency in self-management skills beyond the healthcare settings remains a challenge in everyday clinical practice.

By creating a process that allows both the young person and the doctor to monitor progress and create incentives for maintaining self-care in a fun way would be advantageous. This could be achieved by implementing the principles of gamification. However there are some factors that need to be taken into consideration and areas that will form part of future research. These include evaluating whether the young people would want such a system, what it means to them and how they would use it to help support their care in everyday life.

Engagement with the system based upon gamification may also be dependent upon age, gender and stage of adolescent development, so the time frame for its effectiveness may be restricted owing to loss of interest as the young person matures. Loss of interest may also occur if a young person enters into remission for significant periods of time and be asymptomatic for their medical condition. Therefore they may not feel the need to use the system to continue to learn about self-care behaviours.

As with any game development, implementation and refinement of a range of complex mechanics and balancing them to make it fun, fair and in this case producing positive effects on behaviour is a time consuming process. However these are important components if the benefits of the game are to be maximised. It will be further complicated by the challenges of keeping the game novel and unique so that the

\section{References}

[1] Hagell, A, Coleman, J., Brooks, F. (2013) Key data on Adolescence 2013: The Latest Information and Statistics About Young People Today, Association for Young People's Health.

[2] Harden, P.N., Walsh, G., Bandler, N., Bradley, S., Lonsdale, D., Taylor, J. and Marks, S.D. (2012) Bridging the gap: an integrated paediatric to adult clinical service for young adults with kidney failure. British Medical Journal 344: e3718.

[3] Annunziato, R.A., Emre, S., Shneider, B., Barton, C., Dugan, C.A. and Shemesh, E. (2007) Adherence and medical outcomes in pediatric liver transplant recipients who transition to adult services. Pediatric transplantation 11(6): 608-614.

[4] Hersh, A.O., Pang, S. Curran, M.L., Milojevic, D.S., and von Scheven, E. (2009) The challenges of transferring chronic illness patients to adult care: reflections from pediatric and adult rheumatology at a US academic center. Pediatric Rheumatology Online Journal 7(13): doi: 10.1186/1546-0096-7-13.

[5] Wacker, A., Kaemmerer, H., Hollweck, R., Hauser, M., Deutsch, M.A., Brodherr-Heberlein, S., Eicken A, and Hess, J. (2005) Outcome of operated and unoperated adults with congenital cardiac disease lost to follow-up for more than five years. American Journal of Cardiology 95(6): 776-9. young person returns to use it on a regular basis which is essential for reinforcement of positive health behaviours.

The system should also be designed to discourage people from trying to cheat the system in order to gain the rewards or seek approval from their peers. This would be counterproductive to the requirement that they are actively learning and achieving self-care skills and behaviours. However our premise is that by applying the principles of gamification to the transitional care process the acquisition of new knowledge, self-care and self-management skills would be made more fun and as a result improve the chances of engagement. Even if there were limitations to the effectiveness of the system as long as there were overall improvements in acquisition of skills and in the confidence of the young person to care for themselves it would be successful and as a result has the potential to engage a wider audience. This paper has discussed the application of gamification to transitional care. The initial framework proposed will provide clinicians and healthcare workers with an insight into the use of gamification in a healthcare setting and provide a basis for application to other areas where engagement with knowledge and skills acquisition can be challenging.

\section{Acknowledgements.}

We would like to express our gratitude to the Birmingham Children's Hospital Adolescent Rheumatology Team for their expert advice on both adolescent healthcare and their transitional readiness assessment tools and checklists.

[6] Yeung, E., Kay, J., Roosevelt, G.E, Brandon, M. and Yetman, A.T. (2008) Lapse of care as a predictor for morbidity in adults with congenital heart disease. International Journal of Cardiology 125: 62-5.

[7] Nakhla, M., Daneman, D., To, T., Paradis, G., and Guttmann, A. (2009) Transition to adult care for youths with diabetes mellitus: findings from a Universal Health Care System. Pediatrics 124(6): 1134-41.

[8] Duguépéroux, I., Tamalet A., Sermet-Gaudelus, I., Le Bourgeois, M., Gérardin, M., Desmazes-Dufeu, N. and Hubert, D. (2008) Clinical changes of patients with cystic fibrosis during transition from pediatric to adult care. Journal of Adolescent Health 43: 459-465.

[9] McDonagh, J.E. (2007) Transition of Care. How should we do it? Paediatrics and Child Health 17(12): 480-484.

[10] Shaw, K.L., Southwood, T.R., McDonagh, J.E. on behalf of the British Paediatric Rheumatology Group. (2004) User perspectives of transitional care for adolescents with juvenile idiopathic arthritis. Rheumatology (Oxford) 43(6): 770-778.

[11] Stinson, J.N., Toomey, P.C., Stevens, B.J., Kagan, S., Duffy, C.M., Huber, A., Malleson, P., Mcgrath, P.J., Yeung, R.S. and Fieldman, B.M. (2008) Asking the experts: Exploring the self-management needs of adolescents with Arthritis. Arthritis and Rheumatism 59(1): 65-72.

[12] Suris, J.C., Akré, C., Berchtold, A., Bélanger, R.E., \& Michaud, P.A. (2010). Chronically connected? Internet use among adolescents with chronic conditions. Journal of Adolescent Health 46(2): 200-202. 
[13] Scal, P., Garwick, A. W., \& Horvath, K. J. (2010) Making Rheumtogrow: The rationale and framework for an Internet-based health care transition intervention. International Journal of Child and Adolescent Healt, 3(4): 451-461.

[14] Sawyer, S.M., Drew, S., Yeo, M.S. and Britto, M.T. (2007) Adolescents with a chronic condition: challenges living, challenges treating. Lancet 369(9571): 1481-1489.

[15] Sawyer, S.M., Afifi, R.A., Bearinger, L.H., Blakemore, S.J., Dick, B., Ezeh, A.C., \& Patton G.C. (2012). Adolescence: a foundation for future health. Lancet 379(9826): 1630-1640. doi: 10.1016/S01406736(12)60072-5.

[16] Lieberman, D. (1997) Interactive video games for health promotion: Effects on knowledge, self-efficacy, social support and health, In Street jr, R.L., Gold W.R., Maning T. [eds] Health Promotion and Interactive Technology: Theoretical Applications and Future Directions, Oxon: Routledge), ch, 6.

[17] Bingham, P.M., Bates, J.H.T., Thompson-Figueroa, J. and Lahiri, T. (2010) A Breath Biofeedback Computer Game for Children with Cystic Fibrosis. Clinical Pediatrics 49(4): 337-342.

[18] Kato, P.M., Cole, S.W., Bradlyn, A.S. and Pollock, B.H. (2008) A video game improves behavioral outcomes in adolescents and young adults with cancer: A randomized trial. Pediatrics 122(2): E305-E317.

[19] Wilson, A.S. and McDonagh, J.E. (2012). Moving on: Use of Computer Games During Transitional Care for Young People with Long Term Medical Conditions. In Proceedings of the 6th European Conference on Games Based Learning. Cork, Ireland, October 2012. (England: Academic Conferences Ltd), 542-548.

[20] Suris, J.C., Michaud, P.A., Akre, C. and Sawyer, S.M. (2008). Health risk behaviors in adolescents with chronic conditions. Paediatrics 122: e1113-8.

[21] LaRosa, C., Glah, C., Baluarte, H.J. and Meyers, K.E.C. (2011) Solid-Organ Transplantation in Childhood: Transitioning to Adult Health Care. Pediatrics 127(4): 742 -753, doi: 10.1542/peds.2010-1232.

[22] Sawicki, G.S., Lukens-Bull, K., Yin, X., Demars, N., Huang, I.C., Livingood, W., Reiss, J., Woodm D. (2011) Measuring the Transition Readiness of Youth with Special Healthcare Needs: Validation of the TRAQ_-Transition Readiness Assessment Questionnaire. Journal of Pediatric Psychology 36(2): 160-171.

[23] Ferris, M.E., Harward, D.H., Bickford, K., Layton, J.B., Ferris, M.T., Hogan, S.L., Gipson, D.S. McCoy, L.P. and Hooper, S.R. (2012) A Clinical Tool to Measure the Components of Health-Care Transition from Pediatric Care to Adult Care: The UNC TR(x)ANSITION Scale. Renal Failure 34(6): 744-753 DOI: 10.3109/0886022X.2012.678171.

[24] McDonagh, J.E., Southwood, T.R. and Shaw, KL. (2006) Growing up and Moving on in Rheumatology: Development and Preliminary Evaluation of a Transitional Care Programme for a Multicentre Cohort of Adolescents with Juvenile Idiopathic Arthritis. Journal of Child Health Care 10(1):22-42.0

[25] King, D, Greaves F, Exeter C, Darzi A. (2013) 'Gamification': influencing health behaviours with games. Journal of the Royal Society of Medicine 106(3): 76-8. doi: 10.1177/0141076813480996.

[26] Gabarron, E., Schopf, T., Serrano, J.A., Fernandez-Luque, L. and Dorronzoro, E. (2013). Gamification Strategy on
Prevention of STDs for Youth. Studies in health technology and informatics 192:1066.

[27] Cafazzo, J.A., Casselman, M., Hamming, N., Katzman, D.K., Palmert, M.R. ( 2012). Design of an mHealth app for the self-management of adolescent type 1 diabetes: a pilot study. Journal of medical Internet research 14(3):e70. doi: 10.2196/jmir.2058.

[28] Stinson, J., McGrath, P., Hodnett, E., Feldman, B., Ciaran, D., Tucker, L., Hetherington, R., Tse S., Spiegel, L., Campillo, S., Gill, N. and White, M. (2010) Usability Testing of an Online Self-management Program for Adolescents With Juvenile Idiopathic Arthritis. Journal of Medical Internet Research 12(3): e30, doi: 10.2196/jmir.1349.

[29] Marczewski A. (2013) Gamification a Little on Leaderboards. [online] Available at http://marczewski.me.uk/2013/01/21/gamification-a-littleon-leaderboards/ (accessed 6th December 2013).

[30] Wilson, A.S. and Young, S.P. (2009) The rise of the computer as an assistive technology for education in chronic musculoskeletal disease. In Demir O and Celik C [eds.] Multimedia in Education and Special Education (New York: Nova Science Publishers Inc), ch. 3.

[31] Kamel Boulos, M.N., Hetherington, L. and Wheeler, S. (2007) Second Life: an overview of the potential of 3-D virtual worlds in medical and health education. Health Information and Libraries Journal 24: 233-245.

[32] Parkes A, Sweeting H, Wight D, Henderson M (2013). Do television and electronic games predict children's psychosocial adjustment? Longitudinal research using the UK Millennium Cohort Study. Archives of Disease in Childhood 98(5): 341-8. doi: 10.1136/archdischild-2011301508. Epub 2013 Mar 25.

[33] Hagell, A. (2012). Health implications of new technology. The association for young people's health (AYPH). [online] Available http://www.ayph.org.uk/publications/296_RU11\%20New \%20technology\%20summary.pdf 